\title{
Incursiones en torno a la teorización sobre la transformación del empresariado y la toma de decisiones en la era de la globalización
}

\author{
Incursions around theorizing about the transformation of entrepreneurship and \\ decision-making in the era of globalization
}

\section{Isaac Enríquez Pérez}

Facultad de Ciencias Políticas y Sociales, Universidad Nacional Autónoma de México, México

RESUMEN: Se presenta una categorización de importantes estudios sobre el empresariado realizados en las ciencias sociales latinoamericanas (tomando en cuenta sucintamente los estudios y aportaciones realizados en los países desarrollados).Se identifican y se valoran sus aportaciones para articular una serie de preguntas y argumentos en torno a la importancia de la toma de decisiones de este actor en el contexto de la intensificación de los procesos de globalización impulsados entre otros fenómenos por los constantes flujos de información. Como estrategia metodológica para la construcción de un conocimiento multidimensional sobre el empresariado y la toma de decisiones se propone la identificación, análisis e interpretación de las distintas generaciones de los procesos de calidad y la vinculación al análisis de la organización como formación social donde se recrea el individuo y donde convergen sus intereses y motivaciones, así como la interpretación del sentido de la acción social de los actores para la comprensión de los procesos sociales.

PAlabRas ClavE: Praxis económica; Empresariado; Decisión empresarial; Globalización; Construcción de mercados; Procesos de calidad.

ABSTRACT: A categorization of important studies on entrepreneurship carried out in Latin American social sciences is presented (succinctly taking into account the studies and contributions made in developed countries). Their contributions are identified and valued to articulate a series of questions and arguments around the importance of the decision-making of this actor in the context of the intensification of globalization processes driven among other phenomena by the constant flows of information. As a methodological strategy for the construction of multidimensional knowledge about entrepreneurship and decision-making, the identification, analysis and interpretation of the different generations of quality processes and the link to the analysis of the organization as a social formation where the recreation is created is proposed. individual and where their interests and motivations converge, as well as the interpretation of the meaning of the social action of the actors for the understanding of social processes.

KEYWORDS: Economic praxis; Business; Business decision; Globalization; Market building; Quality processes.

MAD, $\mathrm{N}^{0} 08$ (2003), Pp. 1-38

DOI: 10.5354/0718-0527.2011.14797

(c) CC BY-NC $3.0 \mathrm{CL}$ 


\section{INTRODUCCIÓN}

Es un hecho palpable empíricamente el que la empresa como organización productiva ha modificado profundamente su estructura relativa al proceso productivo y al proceso de toma de decisiones a partir de una transición organizacional que ha desembocado en la optimización del trabajo intelectual de los empleados y, del consecuente proceso de concentración/ desconcentración de la información. Este hecho en sí mismo a finales del siglo XX y en los albores del siglo XXI está desembocando en una reestructuración de la sociedad en su totalidad; no se trata de un determinismo económico sino de un entendimiento de la praxis económica en tanto ella misma formando parte de la praxis humana que son las relaciones sociales históricas que se manifiestan en la reproducción de los individuos en sociedad a partir de la estructuración de organizaciones. Es el empresario en tanto actor socioeconómico uno de los participes en los procesos de construcción de mercados a partir de la especificidad de su toma de decisiones y de sus misiones y objetivos sociohistóricos (búsqueda del beneficio satisfactorio o búsqueda de la maximización de las utilidades en el menor tiempo posible y al más bajo costo); es el empresario un actor que contribuye a la creación de la historia humana al tiempo que se rehace y se redefine en el transcurrir de ella, por lo que nos atrevemos a pensar que esta historia es resultado de la evolución de las estructuras socioeconómicas y culturales, así como de las convergencias y contradicciones entre los intereses y motivaciones de los actores involucrados.

Por lo que dentro de las ciencias sociales latinoamericanas sigue presente la necesidad de teorizar sobre el empresariado en tanto actor socioeconómico y cultural que ejerce poder dentro de la praxis económica a partir de la toma de decisiones en los distintos niveles de la división técnica del trabajo que cada vez más articulan una nueva división social del trabajo y una nueva división internacional del trabajo. ¿Al influir en las instituciones qué importancia tienen estas decisiones empresariales como acción social en el proceso de construcción de mercados en el contexto de la globalización? ¿hasta qué punto esta inquietud ha sido analizada por las ciencias sociales latinoamericanas que teorizan y critican al proceso de globalización y al empresariado? De estas interrogantes se desprende que nuestro objeto de estudio en el presente documento son las investigaciones realizadas en las ciencias sociales latinoamericanas sobre la toma de decisiones del empresariado en sus organizaciones productivas, 
sin dejar de lado la distinción con la producción teórica realizada en otros latitudes. Ambas líneas de investigación constituyen el universo de observaciones necesarias para la clasificación porque aportan los elementos necesarios para identificar y valorar lo teorizado en torno a la empresa y al empresariado y las distintas expresiones de su acción social y, porque son necesarias para rescatar alguna luz para la comprensión y para la eficiente investigación de nuestro objeto de estudio. Se trata pues de mostrar cómo se piensa al empresariado latinoamericano y de asimilar este pensamiento para plantear algunas preguntas y pendientes en torno al estudio de este actor.

A partir del objetivo de estudio definido contemplamos las siguientes tareas: 1) Construir categorías tras el abordaje y análisis de los estudios realizados en América Latina sobre el empresariado para identificar y visualizar sus aportes; 2) esbozar posibles líneas de investigación sobre el empresariado y la toma de decisiones, resaltando la vinculación entre la organización y el actor partiendo de la tesis de que la primera es resultado de la interacción de los individuos y de las posibilidades de estructuración de sus intereses, motivaciones, actitudes y aptitudes, mientras que el segundo sólo puede recrearse y reproducirse socialmente dentro de las organizaciones e instituciones.

Si nos proponemos como tarea, la revisión de una extensa producción académica generada tanto en los países desarrollados como en las ciencias sociales latinoamericanas sobre las empresas y sobre el empresariado, es necesario hacer una "suspensión fenomenológica" que nos permita mirar a los textos con "inocencia", con "ojos de niño", para contrarrestar las tendencias acentuadoras de un pensamiento sociológico que desfigure el contenido transmitido por los autores, con lo cual evitamos la rotulación; y para posibilitarnos una labor hermeneutica en tanto una interpretación y comprensión del sentido de los textos, lo cual también será útil para enfatizar el carácter social del significado de las acciones de los individuos y las comunidades, en nuestro caso, el carácter social del significado y sentido de la toma de decisiones del actor empresarial y sus vinculaciones con la sociedad.

El tratar de evadir la rotulación y la deformación de los contenidos será una labor necesaria para lograr la serie de categorías que revelen la esencia de los estudios elaborados sobre la empresa y el empresariado. Resulta también necesario resaltar que estas categorías elaboradas se sustentan en los textos que se han revisado hasta el momento más que atrevernos a pensar y expresar 
4 | Isaac Enríquez Pérez

que hacemos referencia a todas las investigaciones existentes sobre el objeto de estudio.

La importancia de la toma de decisiones empresariales es necesario situarla en el contexto de la relevancia de la praxis económica como una de las formas de creación social. Es en esta donde tenemos la posibilidad de visualizar los alcances de la acción social del empresariado respecto a la sociedad como un todo. Al tiempo que ubicaremos esta acción social en la discusión sobre la intensificación de los procesos de globalización haciendo particular énfasis en la relevancia de la información para la constitución de estos procesos y el perfil del actor empresarial que la maneja.

\section{SOBRE LA PRAXIS ECONÓMICA}

El ser humano tiene como función histórica vital el crear organización social (Bagú, 1989), por lo que es en sí mismo y en su intergeneración con otros individuos un creador de la sociedad que lo recrea, es decir, es un ser que ejerce la praxis social. "Esto significa que el hombre no es hombre sino dentro de la comunidad humana, pero es él quien genera ésta por medio de una incesante continuidad de actos inteligentes" (Bagú, 1989, p. 15). Esta organización social se genera cuando el hombre resuelve problemas organizativos inmediatos, casi siempre sin proponérselo y excepcionalmente con el objetivo preciso y consciente de hacerlo (Bagú, 1989, p. 16). Es así pues, como existe una praxis social, una praxis económica, un hacer científico, y hasta un hacer artístico y un hacer religioso que interactúan para reproducir socialmente a los individuos que influyen en ello mediante sus intereses y motivaciones. Estas creaciones implican dosis de racionalidad, además de la acción en comunidad, lo cual por supuesto, también implica dosis de emoción e imaginación. Si el ser humano se hace así mismo, hace la historia y se rehace en ella y la transforma, entonces la praxis es un objetivarse, un subjetivarse y un existencializarse.

Por lo que si pensamos que la praxis económica (en conjunción con otros tipos de praxis, es decir, de creación social) es una de las formas que adopta la reproducción social de los individuos y de la sociedad misma, tenemos que pensar también, la importancia que adquieren las organizaciones donde el ser humano se interrelaciona, donde es socialmente determinado y donde construye su propia historia mediante la práctica de su acción social. 
Para un pensador clásico como Carlos Marx, la praxis económica es un fenómeno social pues "los individuos producen en sociedad, y por consiguiente su producción es socialmente determinada" (Marx, 1970, p. 23). La praxis económica es creada por los individuos en sociedad, del mismo modo que es socialmente determinada, de ello se desprende la importancia de las organizaciones productivas que involucran a individuos para crear los satisfactores para las necesidades de la sociedad; es en la empresa donde los individuos socialmente determinados instrumentan sus ideas para producir. Esta praxis económica sólo es generalizable a partir de que tiene su génesis en lo social. Es la satisfacción de las necesidades básicas y las motivaciones de los individuos lo que origina la praxis económica que influye en el todo social.

Dentro de la praxis económica, Carlos Marx asienta que los pensadores clásicos ya habían definido que: "la producción constituye apropiación de la naturaleza por el individuo en el seno de una forma social dada y mediante la misma" (Marx, 1970, p. 27) en función de las necesidades humanas; pensaban que con la distribución se determina la proporción con que participan los individuos en los productos; mientras que el cambio proporciona los productos que el individuo quiere obtener, y por último en el consumo los objetos son disfrutados y apropiados individualmente (Marx, 1970, p. 28). Por lo que rehace estos conceptos sosteniendo que este no es un ciclo que se repite, sino que se renueva, al renovarse el ser humano se transforma, por lo que no debe verse a la producción como el inicio y al consumo como el final, es un todo que no debe dividirse.

La praxis económica comienza desde que se piensa mentalmente el objeto, es decir, al generar ideas sobre cómo satisfacer necesidades se empieza a actuar socialmente. Dentro de la relación dialéctica entre las partes del todo económico, el individuo al producir se transforma a sí mismo. Se da una causalidad dialéctica en la medida en que la forma histórica de la producción determina la forma de consumo, lo mismo sucede cuando se produce y se transforma la idea del objeto, pues al momento de consumir se aspira a un producto mejor o, por lo menos modificado, por lo que las modificaciones sólo llegan con la experiencia social (a lo largo de toda la praxis económica está presente esta experiencia).

Es la praxis económica, el punto de convergencia de la objetivación de la vida humana en la manipulación, apropiación y transformación de la naturaleza, y de la subjetivación de la naturaleza transformada en producto para la sa- 
tisfacción de las necesidades humanas básicas; esto es, la producción es la objetivación de la existencialidad, de la subjetividad y de la emotividad (trabajo humano), mientras que el consumo es la subjetivación de lo objetivado. El trabajo como subjetividad es el acto para producir lo existente en la representación, es la subjetividad corporal y simbólica del trabajador que se objetiva en el producto. La praxis económica también es la convergencia en las ideas del hacer social e histórico que comprende las expresiones estéticas, comunicacionales, científicas, éticas, religiosas, geoestratégicas, políticas, militares, y geopolíticas de los seres humanos.

Todos los elementos que componen a la praxis económica adquieren significado cuando los entendemos como momentos de la reproducción de la sociedad en su totalidad.

De esta forma, es la producción el elemento desencadenante de la praxis económica; por lo tanto, nuestras inquietudes se centran en los actores socioeconómicos que se determinan unos a otros en el proceder de sus acciones sociales enfocadas a la reproducción de la sociedad. Es el empresariado en relaciones de intersubjetividad, materiales, existenciales y de poder con otros actores como el trabajador del conocimiento y el trabajador del hacer y mover cosas, los funcionarios gubernamentales y las instituciones del Estado sobre el hacer gubernamental (Porter, 1993), los funcionarios de organismos multilaterales y los desempleados, quienes en su conjunto al influir en las instituciones participan en la construcción de mercados para la satisfacción de las necesidades básicas de la sociedad a partir de la toma de decisiones ejercida por estos actores.

Pero ¿qué es una decisión enfocada a los procesos productivos y a la construcción de mercados? Una decisión es un proceso que le da forma a una acción social entre actores implicados en los procesos productivos en la totalidad de la praxis económica y que mediante una estructura organizacional y un lenguaje corporativo sustentado en principios comunes referentes a la organización ejercen un grado de autoridad y poder derivados de la negociación, la persuasión y, aun la imposición respecto a la elección, al control de la propiedad y a la manipulación de los factores de la producción para aspirar a la maximización de la ganancia y de la imagen de la empresa a partir de una visión geoestratégica regularmente formada en entornos caracterizados por la contingencia y la incertidumbre. 
En este sentido, la toma de decisiones se caracteriza por ser una respuesta a un problema derivado de la falta de correspondencia entre los objetivos formales de la empresa y la práctica cotidiana de los procesos productivos; por lo tanto, se decide para reducir este diferencial mediante la capacidad para ejercer la acción social por los actores involucrados. La toma de decisiones requiere de la oportunidad para desenvolver esa acción social y de un cierto conocimiento sobre los procesos productivos; por lo tanto, los actores involucrados poseen cierto poder derivado del control de los activos, de los medios de producción y del proceso productivo, el cual no siempre está en manos de los propietarios del capital, sino en manos de altos ejecutivos y analistas simbólicos; derivado además, de la capacidad de negociación y de la sistematización de la información y del conocimiento organizacional y científico.

Es así como el empresariado gesta decisiones para construir su futuro, para transformarse y seguir existiendo más que para seguir sobreviviendo (Acevedo, 1996, p. 72).

2. SOBRE LA GLOBALIZACIÓN COMO PROCESO SOCIOCULTURAL VINCULADO A LA TOMA DE DECISIONES EMPRESARIALES MEDIANTE EL FLUJO Y MANEJO DE LA INFORMACIÓN

Por lo general, en los algunos textos y eventos, en las pretensiones informativas de los medios masivos de difusión comercial, en las plataformas discursivas de las organizaciones gubernamentales, de las organizaciones no gubernamentales, de los partidos políticos, entre otros, encontramos un uso excesivo, paranoico, eufórico y hasta malentendido del concepto globalización; su historia como tal, se ha caracterizado por un ir y venir entre la boca y la pluma de muchos; llegándose incluso a su exageración, a su escepticismo y hasta a su denuncia.

Muchos, por un lado, argumentan que la globalización es un proceso experimentado a partir de las actividades económicas del mundo, y que como tal ha llevado a la reestructuración del capitalismo vía la aplicación del modelo neoliberal; por otro, la globalización es un proceso relacionado con la expansión mundial del capital, de la producción de mercancías, de las telecomunicaciones, y por tanto, se corresponde con la vocación que ha caracterizado al capitalismo desde su nacimiento, es una etapa más de ese modo de producción, por lo que no es una fase específica de la historia; más aún, algunos piensan que la globalización es expresión de una ruptura que lleva a una fase de re- 
construcción del capitalismo tanto como modo de producción como proceso civilizador, es la nueva expresión del capitalismo mundial que se ha manifestado a través del mercantilismo, el colonialismo y el imperialismo (Ianni, 1996 y 1999). Otros más piensan a la globalización no como proceso sino como ideología sustentada en un discurso que entraña intereses de fuerzas poderosas que pretenden instalarlo como un paradigma que encierra falacias como la idea de que es un fenómeno nuevo, homogéneo y homogeneizante que encamina a la democracia, al bienestar universal y a la desaparición progresiva del Estado, ocultando con esa postura ideológica a las relaciones asimétricas que están desembocando en nuevas expresiones de imperialismo en el mundo (SaxeFernández, 1999, 2001; Vilas, 1999). Otros tantos, argumentan que la globalización y las tecnologías de la información que la impulsan no son más que nuevas fábulas imperiales (James Petras, 2001).

Desde una postura más liberal se dice que la globalización es generada por la radicalización y universalización de las consecuencias de la modernidad, o sea, es resultado de la continuidad y expansión mundial de las instituciones emanadas de la modernidad, cuyo dinamismo surge de la separación entre el tiempo y el espacio, del desanclaje de los sistemas sociales que consiste en despegar las relaciones sociales de sus contextos locales de interacción (Giddens, 1990); otros piensan que al hablar de los procesos de globalización se deben introducir los temas del Estado, la soberanía y la autonomía, los cuales resultan ser entidades y conceptos trastocados a la luz de los nuevos procesos donde las decisiones políticas ya no se definen dentro de un solo Estadonación, sino a partir de las pretensiones de un nuevo orden global que se articula desde un derecho internacional, una internacionalización del proceso de elaboración de decisiones políticas, los poderes hegemónicos y estructuras de seguridad internacional, una globalización de la cultura y una economía mundial, para apostar con ello a una cosmopolitan governance o gobernanza cosmopolita (Held, 1995).

Finalmente, en esta apretada síntesis de críticas y teorías de la globalización tenemos a Manuel Castells, quien presenta como presupuestos la idea de que es la revolución en las tecnologías de la información lo que está transformando la base material de la sociedad a pasos agigantados, por lo que las economías de todo el mundo se han hecho interdependientes a escala global creando una nueva forma de relación entre economía, Estado, sociedad y cultura. Esto entraña un nuevo sistema de comunicación con un lenguaje universal, 
lo cual ha dado origen a una "Nueva Economía" caracterizada por estar centrada en el conocimiento y en la información aplicados a la producción, a la productividad y a la competitividad en ámbitos como las empresas, las regiones, las ciudades y los países; por ser una economía global debido a que las actividades económicas dominantes se articulan globalmente, funcionando como una unidad en tiempo real; y porque funciona en redes descentralizadas a todos los niveles que permiten una mayor flexibilidad y adaptabilidad (Castells, 1994, 1998 y 2001).

En una teorización como esta última, se contempla al conocimiento (1) y a la información (2) como factores fundamentales para la articulación de los procesos de globalización. Es la información un factor determinante para los actores que toman las decisiones empresariales; sin ella, los analistas simbólicos estarían imposibilitados para la identificación y resolución de problemas y para la intermediación estratégica; sin ella, la toma de decisiones empresariales no lograría proyectar la productividad y la competitividad como elementos clave de la economía; es la información uno de los factores fundamentales para el desarrollo de las interacciones en red, por lo que con ella se facilita la integración progresiva de unidades en tiempo real y a escala planetaria; sin información, el funcionamiento en red de las economías y de las empresas sería menos flexible y se contaría con una menor capacidad de adaptación rápida a la demanda específica de los clientes. Es más, sin información, sin la tecnología necesaria para lograr una capacidad de gestión y procesamiento, y sin la flexibilidad organizacional operada por los actores, no se contaría hoy en día con las bases para la creación de productividad y competitividad en las empresas. Además, "gran parte de la productividad de la fuerza de trabajo depende, en primer lugar, de la información y del procesamiento de la información y, segundo, de la capacidad del trabajador, de su conocimiento específico de la empresa y de los procesos de la empresa" (Castells, 1998).

Para Manuel Castells, la vinculación entre la información, la organización y los procesos de globalización se presenta de la siguiente manera: "con la nueva tecnología de información puedes tener la flexibilidad de la red y también la coordinación y unidad de proyecto de la decisión con las tareas que hay que realizar. Esto se concreta en la aparición de una nueva forma de actividad económica que llamo la empresa-red y que no son redes de una empresa" (Castells, 1998). Lo sucedido en el mundo de la empresa en los últimos veinte años indica que las grandes empresas se han descentralizado cada vez más, dando auto- 
nomía de decisión a departamentos y divisiones en cada mercado, en cada actividad. El caso de IBM ilustra esto: estaba a punto de desaparecer como empresa y lo que hizo fue crear muchas pequeñas empresas. Cada una de ellas recibe autonomía e incluso compiten en ciertos mercados respecto a cierta línea de producto. La empresa IBM sigue siendo la unidad de capital, la unidad jurídica, la unidad de estrategia financiera, pero cada departamento, cada división, cada mercado nacional y cada sucursal, trabaja con una gran autonomía. Por lo que IBM se convierte en una red de empresas internas más o menos coordinadas entre ellas (Castells, 1998).

Esta innovación en la tecnología de la información y en la gestión organizacional de las empresas fueron necesarias para la reestructuración del modo de producción capitalista, la cual buscó profundizar y perpetuar la lógica capitalista de obtención de ganancias en la relación capital/trabajo, intensificar la productividad del trabajo y del capital, aprovechar las ventajas comparativas para extraer ganancias de todos los rincones del planeta al mundializar la producción, la circulación y los mercados, y contar con el respaldo del Estado para instrumentar recursos y políticas públicas que procuren el aumento de la productividad y competitividad de las empresas y la economía nacional. Las tomas de decisiones empresariales en gran medida se enfocaron a otros procesos, al tiempo que el empresariado interactuaba con otros actores para modificar las instituciones que impulsan la construcción de mercados.

Pero ¿qué significan estas transformaciones? Significa que al transformarse la organización de los procesos productivos que articulan la praxis económica, se transformaron los actores socioeconómicos implicados en ellos, por tanto, son estos actores socioeconómicos quienes al ejercer su poder e influencia social mediante la toma de decisiones materializadas en las redes empresariales y en una visión geoestratégica que entraña cierta idea de cultura y de lo social, son quienes se convierten en uno de los puntos de partida para la articulación del proceso de globalización.

De esta forma, concebimos a la globalización como un proceso sociocultural que hace referencia a fenómenos específicos de la historia humana contemporánea en tanto el mundo se estructura como un todo en sus aspectos económicos, sociales, comunicacionales, informacionales, organizacionales, políticos, culturales, militares, geoeconómicos y geopolíticos. Por lo que es un proceso que se refiere a relaciones virtualmente instantáneas que no reconocen fronteras geográficas y temporales, lo cual implica la intensa y progresiva inte- 
gración de unidades menores en otras mayores a partir de actores socioeconómicos y políticos (pero no sólo de ellos) que toman decisiones sobre las magnitudes de su praxis para reestructurar la sociedad en su totalidad. Es además, un proceso donde surgen y se reafirman identidades y lealtades tanto locales como regionales.

La reconversión de los mecanismos, interacciones e instituciones de la "sociedad nacional" para subsumirse e integrarse a una "sociedad global" son acompañados de inmensos procesos de intercomunicación, interdependencia, y dependencia vía el desarrollo de la informática y las telecomunicaciones, el dislocamiento entre el tiempo y el espacio respecto a la toma de decisiones que influyen a escala global, las fuertes transferencias de capitales especulativos de un ordenador a otro en tiempo real, así como la transferencia de excedentes de la periferia al centro del sistema mundial (3). Así, también entraña relaciones asimétricas entre el centro, la periferia y la semiperiferia, por lo que agregamos que también "la globalización es un proceso de dominación y apropiación del mundo" (González Casanova, 1998).

3. SOBRE LA IMPORTANCIA DEL EMPRESARIADO COMO ACTOR SOCIOECONÓMICO EN LA TEORIZACIÓN DE LAS CIENCIAS SOCIALES

Las transformaciones experimentadas en el mundo durante las últimas décadas son expresión de la evolución de los actores sociales implicados en ellas. El empresariado como actor socioeconómico no ha quedado al margen de ello sobretodo si pensamos que es un actor fundamental en la toma de decisiones enfocadas a la praxis económica.

El nuevo actor empresarial, los cambios que lo acompañan y los que produce son derivados entre otros factores, de las modificaciones en los modelos organizacionales de producción en las empresas, esto es, de la transición de la producción de alto volumen a la producción de alto valor basado en el desarrollo del conocimiento específico satisfactor de necesidades concretas de los clientes vía la multitud de unidades y subunidades descentralizadas unidas a otros grupos también descentralizados que se desplazan por todo el mundo (Reich, 1993 pp. 91-94). Esta transición en la forma de organizar la producción se gestó por el surgimiento de una nueva empresa y un nuevo actor empresarial con características como su actuar a escala global, su concepción que privilegia la información y el conocimientos aplicado al proceso productivo, sus contactos 
con otros actores socioeconómicos y políticos, su capacidad para adaptarse a diferentes entornos socioculturales y, los cambios referidos al proceso de toma de decisiones. ¿Hasta qué punto las ciencias sociales y en especial las ciencias sociales latinoamericanas han teorizado sobre el perfil y la acción social de este nuevo actor empresarial?

Para responder a esta cuestión es necesario definir algunos conceptos como actor socioeconómico y empresariado. Los actores socioeconómicos son aquellos individuos que mantienen relaciones intersubjetivas con otros que poseen cierto grado de poder y autoridad en la toma de las decisiones que modifican los procesos productivos para lograr ganancias satisfactorias, maximizar los intereses de las organizaciones a las que pertenecen (gobierno, sindicatos tanto obreros como patronales, clubes de ejecutivos, etc.), así como impulsar la expansión de una cultura que impacte en el todo social. Mientras que el empresariado son aquellos actores socioeconómicos que al poseer o sin necesidad de poseer los medios de producción, las acciones o el capital ejercen un control sobre la toma de decisiones y los activos de la empresa mediante la información y el conocimiento aplicados al proceso productivo, a su administración y, mediante una visión geoestratégica tendiente a la agregación de valor a la economía mundial, lo cual también implica cierta cosmovisión sobre el mundo y la vida, ciertos principios educacionales, hábitos de consumo y estilos de vida que lo compenetren y lo mantengan cohesionado a su organización y a su clase social. Su acción social está determinada por su relación con otros actores participantes en la praxis social y económica, y en gran medida los aportes de estos influyen en la toma de decisiones del primero. Cuando se trata de un directivo a sueldo, el empresario cuenta con una profunda capacidad, especialización y entrenamiento para la manipulación simbólica tendiente a la identificación y resolución de problemas, y a la intermediación estratégica (Reich, 1993); su capacidad innovadora se orienta a la construcción de una estrategia mundial para alcanzar la ventaja competitiva en las redes empresariales, y es mediante la toma de decisiones como ejerce su control sobre los medios de producción, los activos de la organización y el proceso productivo. Al tratarse de un propietario de los medios de producción y de los activos financieros, el empresario se define por la influencia familiar y por la concentración y centralización de información y capital, lo cual lo coloca como socio mayoritario y presidente del consejo de administración de la empresa, por lo que su papel en la toma de decisiones es determinante. 
Presentamos así una primera distinción en los estudios realizados sobre este actor socioeconómico: por un lado, los estudios y textos sobre la empresa y el empresariado realizados en los países desarrollados, y por otro, los estudios realizados en las ciencias sociales latinoamericanas.

\section{TEXTOS Y ESTUDIOS SOBRE LA EMPRESA Y EL EMPRESARIADO REALIZADOS EN LOS PAÍSES} DESARROLLADOS.

Los documentos que más se generan y proliferan en la literatura de los países desarrollados (y que tienden a difundirse masivamente en América Latina) sobre las empresas y el empresariado son aquellos elaborados en las ciencias administrativas y destinados a la elaboración de proposiciones de corte pragmático que contribuyan a la estrategia y geoestrategia de la empresa. Algunos estudios comprenden desde la evolución de los procesos de calidad, la importancia del conocimiento aplicado al proceso productivo, la importancia de la innovación, la reingeniería y la información, el capital intelectual, la organización inteligente y el papel y formación del líder dentro de la empresa (Valdés, 1994; Drucker 1991, 1994, 1996 y 2001; Kanter, 2000), así como la dirección científica, la mentalidad de cálculo de los managers, la profesionalización de la dirección y administración, los ejecutivos y su papel en la burocracia empresarial (Guillén, 1989; Kanter, 2000), la transición de la producción de alto volumen a la producción de alto valor, las nuevas formas de fabricación y los distintos tipos de división social del trabajo que se forman a partir de ello (Reich, 1993), la importancia de la estrategia empresarial, de la ventaja competitiva, del entorno nacional, del sistema de producción mundial y de la estrategia mundial para hacerle frente, y de las políticas públicas en la construcción de mercados (Porter, 1993).

Si bien, muchas de estas publicaciones no son parte de una investigación en ciencias sociales, resultan importantes por la descripción que elaboran sobre lo que nos atrevemos a denominar como la fisiología de la empresa; son importantes también, por la contribución que hacen en torno a la formación del perfil del nuevo empresario. Son documentos que nos ubican en el plano de los estrategas y de los asesores de empresas que contribuyen con su poder y capacidad en cuanto a la toma de decisiones, a formular lo que hoy conocemos como la "Nueva Economía"; son pensadores muchos de ellos con oficio académico, que gozan de la cercanía y familiaridad con los altos gerentes, ejecutivos y accionis- 
tas que pilotean la economía mundial, por lo que su posición cuenta con una sólida visión geoestratégica que pretende colocar como hegemónica a la nación donde residen. Como estudiosos de las ciencias sociales, estos textos nos incitan a conocer e interpretar los objetivos tácitos de las empresas, e incluso también los "hidden goals" en torno a sus proyecciones en la economía mundial.

Dentro de las ciencias sociales de estos países, en especial en la Sociología Francesa, autores como Alain Touraine esbozan una historia de la empresa, distinguiendo tres grandes etapas y roles distintos para cada una en el desarrollo del sistema capitalista (4). Son estudios que enfatizan la dinámica organizacional de la empresa en el tiempo y la centralidad de la misma en la sociedad contemporánea, rescatando sus especificidades y las circunstancias en que se presenta, rescatando también el perfil del nuevo empresario surgido en Europa ante la avanzada de los modelos organizacionales japoneses y ante la crisis de la sociedad industrial. Es tal la centralidad que el autor le confiere a la empresa al pensar que "la historia del desarrollo industrial de occidente es la del papel en la vida y el pensamiento económicos" (Touraine, p. 1). Es más, "esa transformación de la empresa no afecta solamente al papel de los dirigentes, sino de igual modo el de los asalariados y el de sus sindicatos, y el conjunto de las formas de organización, de autoridad y de toma de decisiones en las empresas privadas o públicas, industriales, comerciales o financieras" (Touraine, p. 1). Destaca la profesionalización de los gerentes que defienden principios de acción inspirados en las reglas del pensamiento racionalista, así como su capacidad para analizar las situaciones y reducirlas a sus componentes elementales, definir y repartir claramente las responsabilidades, asegurar la complementariedad de las funciones jerárquicas y de las tareas funcionales. Sostiene también, que en Europa un empresario relevante es un dirigente que ha logrado asociar estrechamente una estrategia orientada hacia un mercado internacional (estrategia mundial) en transformación continua y una gestión que apunta a incrementar la flexibilidad y autonomía de los elementos de la empresa, integrando también las expresiones del progreso técnico, al tiempo que sabe manejar las relaciones con los sindicatos (Touraine, p. 12).

Lo reflexionado por un sociólogo como Alain Touraine es un enfoque comprensivo que contempla una visión orgánica caracterizada por abordar las relaciones de la acción empresarial con el todo social interpretado históricamente. 
Con una intensa trayectoria en el estudio de las empresas transnacionales y la problemática de la soberanía de las naciones, Raymond Vernon en algunos de sus estudios vincula la relación entre la ética y estas empresas a partir de la crítica inevitable que despiertan debido a su visibilidad, a su gran tamaño, a su condición de extranjería identificable, y a su gran poder de mercado que las lleva a apropiarse del capital del país donde se establecen, e incluso su poder frente a los sistemas políticos. Las criticas responden al temor de los gobiernos por la posibilidad de que escapen a los mecanismos de control ideados por ellos, o porque estas empresas introduzcan elementos que los debiliten, poniendo así en tela de juicio la autodeterminación y la soberanía nacionales. Se trata de encontrar una regulación que medie en las disputas nacionales y que delimite el accionar y las obligaciones de las empresas en el mundo. La necesidad creciente de inversiones en los países desarrollados encuentran en las empresas multinacionales provenientes de los países avanzados el abastecimiento de capital, tecnología y personal directivo, pero el precio a pagar por parte de los primeros es alto en lo económico y en lo político, pues sienten vulnerada su independencia y soberanía (Vernon, 1973), por lo que el autor analiza la compatibilidad de las empresas multinacionales y los Estados nacionales respecto a sus objetivos y expectativas (Vernon, 1980).

Además, se identifican una serie de enfoques variados acotados o parciales sobre los estudios empresariales en estos países:

1) La concepción ortodoxa del libro de texto (5)con acentuadas ausencias en el análisis de los actores y del individuo (por lo que entra en un conflicto teórico con el individualismo metodológico) y en la explicación de la organización económica, enfoca su análisis al ámbito de un conjunto de producción (aunque inmediatamente cambia al análisis del comportamiento en los mercados de insumos y productos) y sostiene a la racionalidad como ilimitada. Señala además que las empresas se caracterizan por las transformaciones tecnológicas de las que son capaces mediante conjuntos o funciones de producción, por ser actores unitarios y económicamente racionales al maximizar el beneficio o el valor presente, por operar en mercados de bienes homogéneos (estos mercados se piensan como instantáneos para insumos y productos), por estar guiadas por las fuerzas del mercado para que tomen las decisiones de producción que constituyen una parte de la respuesta global de la asignación social de los recursos, y por ser la depositaria de conocimiento productivo. "Los tratamientos convencionales de la teoría moderna presentan a las empresas como conjuntos 
de producción que persiguen el beneficio. La motivación del beneficio podría racionalizarse como un reflejo de los intereses (unánimes) de los accionistas bajo los supuestos prevalecientes de mercados completos, competencia atomizada y contratos perfectos [...] Al igual que los consumidores, las empresas son primitivos lógicos del sistema teórico" (Winter, 1996, p. 250).

2) La concepción de la ortodoxia del ensayo de trabajo analiza la estructura de las relaciones existentes entre los actores involucrados en la empresa, abordando los problemas sustantivos de los incentivos, información y control entre propietarios y administradores o entre administradores y trabajadores, los equilibrios no cooperativos y los resultados que son "óptimos condicionados" a partir del imperfecto incumplimiento forzoso de los contratos; concibe también a la racionalidad económica como ilimitada en el ámbito del intercambio (Winter, 1996).

3) El enfoque del arbitraje internacional con G. D. A. MacDougall como principal exponente explica el origen de las empresas transnacionales y argumenta que el capital fluye de países donde es abundante a donde es escaso, identifica también los diferenciales de las tasas de interés y las privilegia por encima del control de inversiones y el arraigo del capital.

4) El enfoque de las ventajas de propiedad a nivel firma con Stephen Herbert Hymer (1972, 1976 y 1979) como uno de sus representantes, propone que cada empresa en la lógica de la competencia trata de desarrollar activos tangibles e intangibles que significan ventajas para los mercados, explicando también por qué las inversiones fluyen entre países desarrollados.

5) La teoría del ciclo del producto con Raymond Vernon como uno de sus exponentes, desagrega el proceso en tres frases (el surgimiento de nuevos productos, los cambios que los mejoran y estandarizan y, su eventual desaparición), llamando la atención sobre la innovación tecnológica y cómo se logra una localización e ingreso a los países desarrollados vía la inversión.

6) El enfoque de la internalización con Ronald Harry Coase (1994 y 1996 (6) como uno de sus autores, hace referencia a la conexión entre la organización y el costo, a la forma en que las empresas obtienen beneficios de las ventajas de propiedad, además de sostener que el tamaño y alcance de la empresa están determinados como factor principal por los costos comparativos de las transacciones que se realizan a través del mercado o dentro de la misma empresa. Reconoce que los distintos procedimientos para la organización (o "modos de gobernación") de las transacciones difieren en sus costos. 
7) El enfoque de los costos de transacción (influido tanto por el enfoque anterior como por su principal exponente) en el que resaltan nombres como Oliver E. Williamson (1989 y 1996), Sidney G. Winter y David J. Teece, señala que las imperfecciones existentes en el mercado son internalizadas por las empresas a manera de costos; estos costos de transacción constituyen la organización económica a través del tiempo debido a la presencia de innovaciones organizativas que estimulan dificultades transaccionales ya experimentadas, entonces las empresas que introducen estas innovaciones crecen y prosperan a costa de sus competidores, por lo que su análisis se ubica en los procesos de intercambio concibiendo a la racionalidad económica como limitada. Además, con este enfoque se analizan distintas instituciones económicas y sus implicaciones en las políticas públicas y laborales, así como las expresiones de integración vertical de las organizaciones encaminadas a la reducción de riesgos, y las limitaciones burocráticas impulsadas por el crecimiento de la empresa, señalando además que el comportamiento económico es algo intencionalmente racional (Williamson, 1989).

8) La teoría de la localización cuyo mayor exponente es Michael Porter, argumenta que las empresas se localizan en países estables, con monedas fuertes y sistemas políticos en equilibrio, con culturas similares, recursos naturales aptos para ser explotados, y para generar una ventaja comparativa. Estas empresas nunca se localizaran en países que carecen de infraestructura física (insumos, telecomunicaciones) e institucional (marcos legales y mano de obra barata, régimen fiscal); esta localización es parte del proceso de decisiones de la organización para aprovechar de mejor manera la fase productiva.

9) El enfoque de la economía evolutiva con Armen Alchian como su principal teórico, mediante una explicación evolutiva derivada de la atención hacia el comportamiento económico observado señala el aspecto dinámico de lo inevitable de las decisiones erradas en contextos de incertidumbre, y el papel activo del ambiente económico en la definición de los errores y en su supresión. Analiza los procesos de producción (pero bajo el concepto de rutinas organizativas señala la relación de las empresas con los propietarios, los clientes y los proveedores de insumos) y concibe a la racionalidad económica como limitada, así como la manera en que los modelos se reproducen en el tiempo en medio de una rotación continua en la población de individuos que exhiben el modelo; aunque su principal problema teórico a resolver es la comprensión de los pro- 
cesos de cambio corrientes, interrelacionados, en la tecnología y en la organización (Winter, 1996, p. 260).

10) El enfoque de las ventajas competitivas a nivel firma, industria y país en el que de nuevo resalta Michael Porter, intenta vincular estos tres niveles señalando la realimentación que existe entre ellos.

11) La teoría de las redes con Bernard Michael Gilroy (1993) y Hace como exponentes, argumenta que el proceso de internalización puede ser complejo; explica además las características de las redes señalando que al ser estas horizontales no carecen de jerarquías.

12) El paradigma ecléctico propuesto por John Dunning (1993), se apoya y sintetiza corrientes como la de las ventajas de propiedad, de la internalización y de la localización. Expresa que la capacidad de las empresas para satisfacer los mercados se genera por la posesión y acceso a tecnología, información y productos intermedios, lo cual también influye en la expansión a un mercado externo. Explica el cómo, cuándo y por qué ocurre esta expansión.

Estos variados enfoques se encuentran arraigados en una óptica neoclásica que visualiza el funcionamiento de la organización y sus vinculaciones con otras unidades y países mediante expresiones geoeconómicas, tecnológicas, de propiedad y de gestión, sin acentuar en algunos casos el énfasis en el empresario como actor socioeconómico. Se analiza a la empresa en su vinculación con el sistema económico y político de las naciones, así como los peligros que corren los países receptores de sus inversiones (como en el caso de Vernon). Además, aportan una enorme variedad de conceptos y categorías para el análisis de las organizaciones productivas y para la comprensión de la intencionalidad y sentido de las acciones de sus actores. Mencionados que son enfoques acotados o parciales por enfatizar problemáticas definidas y soluciones específicas para mejorar el accionar de las empresas.

5. El EMPRESARIADO COMO OBJETO DE ESTUDIO EN LAS CIENCIAS SOCIALES LATINOAMERICANAS

En las ciencias sociales latinoamericanas, por lo general y no en todos los casos, han concebido al empresariado en tanto actor político en relación al gobierno y al Estado, ya sea como grupo de presión, ya como entidad de consulta, ya como generador de opinión pública, ya como participe en los partidos políticos y en los procesos electorales, ya como aliado y beneficiario en la aplicación de determinada política económica (como es el caso de las privatizaciones que 
fortalecieron a grandes grupos empresariales); ya como actor que incide en las decisiones político-estatales para favorecer sus intereses particulares y de clase, rompiendo con ello la supuesta lógica de autorregulación del mercado, contemplando las relaciones de patrimonialismo y corrupción (Garrido, 1988; MiIlán, 1988; Garrido y Puga, 1990; Pozas y Luna, 1991; Puga, 1993; Tirado, 1994; Salas-Porras, 2000; Vidal, 2000). En estos estudios es importante el análisis de los proyectos y los discursos empresariales en torno al papel del Estado en la economía y en torno a las estrategias de desarrollo adoptadas. A estos estudiosos los podemos colocar como analistas sobre la propensión política del empresario o sobre las relaciones estatocéntricas del empresariado. Se enfocan al estudio de la reestructuración económica presente desde la década de los ochenta y el protagonismo que ha adquirido el empresariado en sus relaciones con los actores del Estado y el sistema político; se investiga sobre las transformaciones estructurales de la economía latinoamericana y las relaciones que surgen entre los empresarios y el gobierno, así como las tensiones entre estos y el resto de los actores sociales. Se analiza al empresario a partir de su presencia en puestos administrativos y en asesorías presidenciales, así como el papel de las organizaciones patronales en tanto representantes políticos del empresariado; se analiza la coincidencia de proyectos entre los funcionarios de los gobiernos y los grupos empresariales hegemónicos; las tensiones entre estos actores respecto a la demanda empresarial sobre el fin del corporativismo que se sustentaba en el control del sector obrero, campesino y popular, y el tránsito a un neocorporativismo vinculado a la toma de decisiones a partir de la negociación entre el gobierno y el empresariado (Garrido y Puga, 1990).

Para el caso mexicano, uno de los argumentos que sostiene a este tipo de estudios se presenta ante el surgimiento de una conciencia política en el empresario tras ser excluido del pacto de unidad nacional derivado de la relación del Estado Posrevolucionario con las organizaciones de masas; era una doble relación entre el Estado y el empresariado, por un lado se protegía y se alentaba la expansión de este último y se le incluía informalmente en las decisiones estatales, pero por otro se le negaba formalmente como actor político, lo cual condujo a conflictos, desacuerdos, descontentos y reclamos; pero no solamente las necesidades políticas del empresariado llevaron a estos conflictos, también fueron motivo de fricciones la excesiva participación estatal en la vida económica y sus tendencias monopólicas. Esta nueva conciencia política y la consiguiente acción política, han convertido al empresariado en un actor cen- 
tral de las transformaciones económicas y políticas de las últimas décadas (7). Se trata pues, en esta relación, de equilibrar y hacer compenetrar los intereses del Estado y del capital, pero también de señalar las divergencias y conflictos entre ambos.

Estos estudios, se alejan de interpretaciones ortodoxas, descontextualizadas y carentes del análisis de la especificidad de las clases sociales, quien han pensado al Estado como una serie de instituciones representantes de los intereses de la clase capitalista, sin tomar en cuenta las contradicciones que surgen de sus interacciones; los estudios sobre las oligarquías mostraban una similitud entre el poder económico y político o la relación directa entre ambos en la que un poder deriva de otro, o en la que las acciones de uno son extensiones o fortalecimientos del otro. Además, estos análisis pretenden alejarse de la creencia de que el poder empresarial está condenado a desaparecer, por lo que se piensa que es una pérdida de tiempo el estudio del mismo, lo adecuado en estas interpretaciones era el enfocarse al estudio de los grupos sociales organizados con pretensiones revolucionarias (Puga, 1993, p. 47).

En una perspectiva que extiende su análisis a la región latinoamericana, se argumenta que en países que vivieron regímenes militares, después de transitar a gobiernos civiles se recurrió a los vínculos con el empresariado para ganar cierta dosis de legitimidad, sobretodo en la combinación con procesos de apertura comercial y desregulación de las economías nacionales; se piensa, además, que el Estado sigue siendo una arena política donde se disputa el predominio de los intereses de las clases sociales, en dicha arena es el empresariado un actor que se impone al resto (Garrido, 1988; Sidicaro en Tirado, 1994).

Estos estudios permiten comprender al empresario en una perspectiva más integral que complementa a la concepción que lo relaciona con la tenencia de los medios de producción, y la extiende a una concepción que contempla ciertos patrones culturales que constituyen la identidad de la clase. Se señala la expansión del actuar del empresariado a esferas como la administrativa, la partidista y la cívica a partir de lo cual se constituye como grupo gestor de los intereses económicos, como agente social en tanto penetra ideológicamente y como agente político en tanto accede al sistema de partidos (Millán, 1988). De igual manera, se pone el acento en los vínculos y relaciones del empresariado con otros actores y, en las acciones de estos últimos que pueden perturbar los objetivos de las grandes empresas, sobretodo las inestabilidades políticas, las orientaciones ideológicas y las sucesiones presidenciales que se generan al in- 
terior del gobierno. Además, el análisis de la interacción entre estos actores nos permitirá comprender e interpretar su influencia en las instituciones para la construcción de mercados.

Otros científicos sociales enfocan su análisis al estudio sobre la propensión geoeconómica del empresariado para pensar la expansión internacional de las grandes empresas latinoamericanas (Chudnovsky, Kosacoff, López, y Garrido, 1999) y en específico de las mexicanas (Basave, 2000; Vidal, 2000), la formación de alianzas estratégicas para constituir redes empresariales (SalasPorras, 1998) y las nuevas estrategias de expansión empresarial para enfrentarse a la globalización, o bien, para ser motor de la misma (Basave, 2000; Vidal, 2000). Es de notar que la internacionalización de las empresas latinoamericanas generalmente fue motivada por el proceso de reestructuración económica fomentado por el Consenso de Washington. La dicotomía se planteaba entre "el vivir o el morir", entre el confrontar la avanzada del capital extranjero ante la apertura de las fronteras, o el emigrar hacia otras latitudes. Se afirma que la internacionalización es catalogada por los empresarios como una respuesta al agotamiento del Estado desarrollista y su pretendido modelo de sustitución de importaciones mediante la industrialización hacia adentro y el proteccionismo que los cobijaba de la avanzada contundente del capital multinacional. Los procesos de reestructuración de la economía vía las privatizaciones favoreció la proyección internacional de las empresas latinoamericanas, pues en gran medida liberalizaron la producción y comercialización, y afianzaron y fortalecieron a los grupos económicos internos, los cuales en un futuro muy corto fueron subsumidos por los capitales europeos y estadounidenses, tal es el caso de la banca.

La propensión a la expansión e internacionalización de las grandes empresas latinoamericanas está orientada, según estos estudios, por la necesidad de resistir o insertarse a las tendencias de los procesos de integración, regionalización y globalización; por la expansión hacia mercados cautivos que proporcionen los suficientes recursos naturales y los espacios de comercialización que sustituyan a los pocos que se tienen en los países de origen de las empresas; por la necesidad urgente de absorber los avances tecnológicos y el know how en las esferas tecnológica, financiera, productiva, comercial y organizacional al insertarse en las redes empresariales, además de la necesidad de fusionarse con un socio prestigiado o alguna marca reconocida. El proceso de internacionalización es definido como un fenómeno económico asociado al desempeño 
empresarial (Kosacoff, 1999, p. 105). La conformación de un esquema de IED de las empresas latinoamericanas se negocia y se procesa al interior de la organización a partir del acceso a mercados financieros internacionales. Es más, estos procesos de internacionalización de las firmas latinoamericanas han sido necesarios para la reestructuración organizacional que les permita competir en la economía local. Y más aún, entre las motivaciones que impulsan la internacionalización de las empresas se encuentran la necesidad de establecerse cerca de los clientes aprovechando las similitudes culturales, o bien forjando nuevas pautas culturales de consumo; la necesidad de evadir las barreras arancelarias; la necesidad de acceder a materias primas; además de la necesidad de acceder a amplios mercados abiertos por los procesos de regionalización y subregionalización de las economías latinoamericanas.

El acceso a mercados internacionales ha permitido a las grandes empresas latinoamericanas el adquirir recursos clave y desarrollar activos estratégicos; además de la generación de encadenamientos en el proceso productivo, el desarrollo y capacitación de los recursos humanos, la búsqueda de la reinversión de utilidades en el país de origen, integración a las redes empresariales globales para instrumentar negociaciones mayores, impulso a la exportaciones; todo ello a partir del estímulo y desarrollo de las operaciones tecnoproductivas y de la evolución del factor organizacional de la empresa. En este proceso, el entorno económico e institucional en el que se desenvuelven las empresas condiciona y favorece los procesos de ganancia y competitividad (Kosacoff, 1999, p. 130).

Los procesos de internacionalización apuntan a aumentar el tamaño de las empresas, a mejorar su competitividad internacional, a diversificar geográficamente sus inversiones para dispersar riesgos y obtener beneficios, y a desarrollar la capacidad de management por la actuación en distintos mercados (Garrido, 1999). Las decisiones de estas empresas se enfocan al hacer frente a desafíos regionales y globales al competir con las redes empresariales mundiales que cada vez más apuestan por absorber a las empresas latinoamericanas; aunque es de notar también, que las empresas de la región apuestan por fusionarse o adquirir a empresas del país donde se establecen o bien, a asociarse a las redes empresariales. Una de las estrategias destacada de las empresas mexicanas en sus procesos de internacionalización es la búsqueda de alianzas que les permiten extenderse a los mercados mundiales, ya sea con la facilitación de las exportaciones o en actividades que agregan valor (de 1993 a 1998, 29 de los 
60 grupos no financieros más grandes del país han realizado esta estrategia); para Alejandra Salas-Porras, la red de compañías aliadas es muy dinámica y contradictoria; sin embargo, la necesidad de lograr ventajas complementarias acerca mucho a las empresas nacionales y extranjeras; el socio mexicano generalmente busca ser más activo en el ámbito internacional, ganar acceso a los mercados externos y a la tecnología de punta, mientras que el socio extranjero busca aprovechar el potencial de crecimiento mexicano; estas alianzas estratégicas juntan a dos o más empresas globales en una red empresarial, cumpliendo cada una muchas veces funciones distintas; algunas son pasivas o activas en cuanto a la toma de decisiones que afectan la articulación y dinámica de la red (Salas-Porras, 1998).

Estos estudios sobre la propensión geoeconómica de las empresas nos señalan el carácter activo del empresariado latinoamericano, y sus tendencias a la ocupación de mercados para responder a la avanzada de las redes empresariales globales. No es que el empresariado latinoamericano carezca de la capacidad para tomar decisiones en un contexto caracterizado por la mundialización de los capitales hegemónicos, se trata de las motivaciones diversas que lo impulsan a transnacionalizarse y a evitar su disolución ante estas redes empresariales (8). En estas investigaciones interesa el sector empresarial en relación al conjunto de la economía nacional, a sus transformaciones y a la inserción de esta en el avance de la economía mundial (Basave, 2000; Vidal, 2000), esto es, a las empresas se les piensa en tanto constitutivas del sistema económico de los países, además de relacionar a este con el papel que ocupa en la nueva división internacional del trabajo y en el proceso de desarrollo.

Otros estudios con un fuerte contenido y análisis derivados de las ciencias económicas señalan la importancia de la empresa en tanto indicador económico vinculándolo a la totalidad del sistema económico nacional, e incluso relacionándola como indicador a partir de sus ventas anuales para comprender el avance de los países hegemónicos en su rivalidad por dominar el sistema mundial (Bergesen y Fernández, 1999); algunos análisis distinguen entre micro, pequeña, mediana y gran empresa señalando en números absolutos y relativos el total de unidades económicas, la cantidad de empleados, las ventas anuales, su vinculación con los sectores económicos, su contribución al Producto Interno Bruto (PIB), su evolución en el tiempo y la importancia y deficiencias de sus estrategias de producción y comercialización (Rueda, 2001). 
La micro, pequeña y mediana empresa por lo general se vinculan al proceso de subcontratación donde una empresa contratista las subcontrata porque los costos son más bajos, la mano de obra es más dócil, fomenta la desincorporación de fases del proceso productivo y de servicios, se reduce el número de empleados, se debilitan los sindicatos, por lo que se otorgan salarios y prestaciones bajos; además, de que se cuenta con horarios flexibles, con una mayor especialización en el proceso, además de que se tiene una ausencia de sindicato en la empresa subcontratada, y se cuenta con una mayor calidad en la producción de esta última. Por otro lado, las empresas subcontratistas al integrarse en las redes empresariales buscan un aumento en sus ventas, una estabilidad en la demanda de sus bienes y servicios, además de un aprovechamiento en la transferencia de tecnológica. A partir de esta subcontratación se elaboran estudios sobre las empresa maquiladora (Morales) entendiéndola como un eslabón integrado a las redes empresariales mediante el ensamblaje y fabricación simultánea y dispersa del producto tras el libre flujo de sus partes; sin embargo, al igual que la categorización que distingue entre distintas empresas, estos estudios contemplan a esta empresa maquiladora como parte de un sistema económico caracterizado por los flujos de Inversión Extranjera Directa (IED) que se destinan a los países latinoamericanos, las exportaciones que realizan los países centroamericanos, el número de establecimientos y empleados, así como el país de procedencia de estas empresas y la ubicación y transformación geográficas que tienen en países como México.

Estos estudios que denominamos como caracterizadores de la empresa en tanto indicador que responde a la dinámica del sistema económico, nos permiten conocer la importancia de las contribuciones de los distintos tipos de empresas respecto a las variables macroeconómicas de los países, relacionándolo con la lucha por la hegemonía mundial y con la composición económica de los países latinoamericanos, así como interpretar el potencial de los sectores económicos, y la orientación de la fuerza de trabajo en torno a estos. Además de mostrarnos la importancia de la integración de unidades empresariales menores en la formación de redes empresariales.

Finalmente, contamos con los pocos estudios que analizan la dimensión de la toma de decisiones del empresariado a partir de la concepción de la empresa como una organización que ha atravesado un proceso corporativo. Algunos estudios parten de la idea de que la estructura y organización corporativa en las grandes empresas mexicanas se funda en una creciente separación entre 
la propiedad y el control, donde los altos ejecutivos y expertos juegan un papel importante pese a la persistencia de la presencia de los miembros de la familia en los consejos de administración. Estos expertos son necesarios para la orientación en la toma de decisiones respecto al proceso productivo, el financiamiento, las alianzas estratégicas y la integración a las redes empresariales, ya que se decide en términos de dimensiones globales de las acciones y de procesos de internacionalización de estas grandes corporaciones (Salas-Porras, 1992 y 1997). La tesis se sustenta en el hecho de que el surgimiento y desarrollo de los cuerpos corporativos producen cambios en la estructura política porque crean un nuevo actor social, conformado por los altos ejecutivos y el staff corporativo, que tiende a concentrar una capacidad de decisión y acción dentro de la corporación en las relaciones con los accionistas, con las agencias gubernamentales y con el Estado, y la sociedad en general, y porque al mismo tiempo modifican el peso y las funciones de los más importantes propietarios o accionistas. Se analiza también la manera en que los cambios de la estructura y estrategia corporativas responden, afectan o interactúan con la proyección global de las grandes corporaciones mexicanas. Se identifica que durante la década de los noventa la organización de las grandes corporaciones mexicanas se asemeja cada vez más a la que impera entre las corporaciones de los países desarrollados, en cuanto a la estructura organizacional, los patrones de control y entrelazamiento; esta convergencia organizacional ha facilitado en gran medida la comunicación, interacción e integración, no sólo con los circuitos financieros, productivos y tecnológicos transnacionales, sino también con la red corporativa mundial.

Resulta interesante y provechoso que el marco categorial de esta autora es integrado por términos como decisión, control corporativo, administración del control, articulación racional, patrones de entrelazamiento corporativo; abordando todo ello mediante la metodología del análisis de redes, donde las relaciones de poder se encuentran a través del entrelazamiento de directorios corporativos y sus relaciones con las redes de política y otras instituciones empresariales. Y es mediante ello, como se llega a conclusiones como la siguiente: la expansión de las empresas mexicanas hacia mercados globales transforma la organización y estructura corporativas de distintas formas.

En este mismo tenor existen otros pocos trabajos que incitan a la conceptualización de la nueva empresa y los nuevos actores empresariales en torno al proceso de globalización y la reconfiguración de los mercados (Pérez y 
Gándara, 2001; Acevedo López, 1996 y 1998). Se trata de pensar a los altos ejecutivos de las grandes corporaciones mexicanas a partir de la consideración de la propiedad corporativa y de la concepción de la corporación transnacional como un tipo de organización moderno (Pérez y Gándara, 2001). Se piensa que los mercados al dejar de ser nacionales requieren de decisiones que apuntan a redefinir las unidades políticas, además, al tiempo que estos mercados se hacen mundiales estas decisiones también se redefinen; esta nueva organización de la producción transmite la lógica de su racionalidad a todo el modo de ser de la sociedad en su cultura y en su sentido, por lo que se concibe a la empresa como una organización que es una creación humana, un instrumento cuya arquitectura define la potencialidad de los colectivos (Acevedo López, 1998, 161, 162 y 182). A decir de esta autora, "...la existencia de la nueva forma de organización red significa una nueva forma de proyectar, organizar y ejecutar la toma de decisiones que necesita redefinir las estructuras de poder todo lo cual permite explicar por qué se están mundializando las formas de organizar los procesos productivos y con esto trastocar las formas de distribución de la riqueza" (Acevedo López, 1998, p. 164); esto ha implicado el surgimiento de nuevos cuadros directivos que no necesariamente se caracterizan por la propiedad de los activos de las empresas para ejercer la toma de decisiones ya que cuenta más su capacitación para dirigir equipos de especialistas (Acevedo López, 1998, p. 168); se toma en cuenta además, la desconcentración de las decisiones operativas, la importancia de las nuevas tecnologías y la reacción de América Latina en tanto sistema económico ante la formación de esta empresa red (Acevedo López, 1996 y 1998).

6. SOBRE LOS RASGOS PENDIENTES EN TORNO AL ESTUDIO DEL EMPRESARIADO COMO ACTOR SOCIOECONÓMICO EN LAS CIENCIAS SOCIALES LATINOAMERICANAS

Aunque se han producido estos acercamientos fructíferos y esenciales al estudio de la nueva empresa y del perfil del nuevo empresariado, existirían otras vertientes de trabajo que nos permitirían pensar del todo al empresario como un actor socioeconómico y cultural que a partir de la centralización/descentralización de la toma de decisiones respecto al proceso productivo está articulando nuevas dimensiones de la praxis económica que conducen a la redefinición de la sociedad en su totalidad. La necesidad de contemplarlo como actor socioeconómico y cultural dentro de las ciencias sociales latinoamerica- 
nas fomentaría el alejamiento de las imprecisiones conceptuales que se tienen en torno a procesos como la globalización, la integración y la regionalización, sobretodo si pensamos en la forma en que América Latina se inserta en tanto sistema económico a estos procesos.

El problema de la construcción de mercados como fundamental para estructurar las sociedades a partir de las acciones sociales y de la racionalidad de distintos actores que influyen en las instituciones, requiere plantearse preguntas como las siguientes: ¿qué papel juegan las decisiones empresariales en la construcción de los mercados? y más aún, las relaciones de intersubjetividad, de existencialidad y de poder entre el empresariado y otros actores sociales como el Estado, ¿de qué manera contribuyen en este proceso de construcción de mercados? ¿cuál es la racionalidad y las motivaciones del empresariado en esta etapa específica de la historia y cuál es el tipo de sociedad que pretende en el ejercicio de su praxis económica y en el proceso de centralización de la toma de decisiones? más aún, ¿qué representa la América Latina en esta construcción mundial de mercados? ¿qué actores socioeconómicos regionales están involucrados en estos procesos?

Si pensamos que el empresariado latinoamericano formado y consolidado en el periodo del Estado desarrollista tiende a su desaparición, o bien, a una transformación de sus funciones en el proceso productivo ante los procesos de privatización, ante la reestructuración de las economías domésticas, y ante la avanzada de las redes empresariales y del sistema bancario mundializado, tenemos que entre las tendencias que enfrentan las empresas latinoamericanas en el proceso de internacionalización en aras de una integración regional y global son la capacidad que tienen las redes empresariales globales para fusionarlas o adquirirlas. A pesar de que existieron grupos empresariales locales que se beneficiaron con las privatizaciones de las empresas paraestatales, con los procesos de fusión y adquisición fomentados por las redes empresariales, solo han servido como una estación de paso del capital que se traslada cada vez a las redes empresariales globales. Ante ello, nos planteamos la necesidad de avanzar en el conocimiento del tipo de decisiones que toma el empresariado latinoamericano para entender si este actor socioeconómico es activo o pasivo, si está condenado a perecer o si está en proceso de redefinición de sus funciones y de sus decisiones ante la avanzada de las redes empresariales globales sobre la región. 
Al insertarse a los mercados internacionales, las empresas latinoamericanas se están viendo en la necesidad de reestructurar sus modelos organizacionales, lo cual implica cambios de los actores que toman las decisiones, y cambios también en la relación capital/trabajo. Este tipo de empresariado latinoamericano adoptó un carácter global, aunque gran parte de sus operaciones las sostiene en la "madre patria", Carlos Slim y Lorenzo Zambrano son un ejemplo claro de ello.

El nuevo empresariado y sus procesos de toma de decisión se entienden a partir de la interacción con otros actores sociopolíticos y económicos que también le dan sentido a su acción social, y a partir de otras organizaciones e instituciones que participan en la construcción de los mercados. Las relaciones del empresariado con el Estado y con los organismos internacionales tienen que entenderse no sólo en tanto una lucha por el poder político de una sociedad, sino que es necesario trascender a dimensiones o categorías que reflejen el sentido de las políticas públicas en tanto instrumentos del Estado para construir cierto tipo de sociedad, y en tanto instrumentos que reflejan la convergencia de distintos actores en ellas y las contradicciones que se presentan entre los actores participes en la construcción de mercados.

Una de las líneas de trabajo que proponemos parte de la necesidad de analizar la evolución del actor empresarial a lo largo de los procesos de calidad, pensando que es en ellos donde cuanta con un alto margen de acción y de toma de decisiones. Una categorización adecuada sobre los procesos de calidad al interior de la empresa es la elaborada por Luigi Valdés, quien sostiene que han transitado por generaciones como las siguientes: Primera generación, donde la calidad se concibe como un proceso para medir y controlar al producto final; Segunda generación, caracterizada por el hecho de que del proceso controlado se obtiene información que influye en la toma de decisiones; Tercera generación en la cual, al ser una estrategia de negocios se busca adecuar la producción a los retos del mercado; Cuarta generación en la que con los procesos de mejora continua se orienta a mejorar y optimizar las actividades de las empresas hacia el cliente externo, además de que se delega la autoridad y responsabilidad a cada integrante; Quinta generación, caracterizada por la reingeniería y calidad total que rediseñan a la empresa con procesos completos caracterizados por la agregación de valor hacia el cliente, buscando reducir la burocracia, subcontratar servicios y tender a que los ciclos de producción sean más cortos, contando con formación de equipos auto-dirigidos, para desembo- 
car finalmente en una redefinición del concepto de trabajo; Sexta generación, donde la estrategia incorpora el pensamiento innovador de todos los miembros de la empresa; además de pretender una estructura flexible de acción bajo un esquema centralizado/descentralizado orientado a crear y agregar valor al cliente vía el conocimiento, así como la sistematización y estructuración del capital intelectual de la empresa para lograr un crecimiento sostenido (Valdés, 1994, pp. 117-161).

Si en estos procesos de calidad, el empresariado plasma la especificidad de su acción social creando, recreando y orientando la toma de decisiones, entonces surgen preguntas como las siguientes: ¿Cuál es el sentido de la toma de decisiones en cada una de estas generaciones del proceso de calidad? Si los procesos de calidad han evolucionado ¿cuáles son las características de la empresa y del empresariado en esas transiciones? ¿cuál es el sentido de la acción social del empresariado en cada generación del proceso de calidad? ¿cuales fueron los elementos societales que permitieron que dentro de la empresa a partir de su división técnica del trabajo y posteriormente a partir de la división social del trabajo se constituyera una fábrica global articulada a un shopping center global, los cuales son hoy algunas de las expresiones de los procesos de globalización?

Podemos pensar que en la caracterización elaborada por Luigi Valdés respecto a la evolución de los procesos de calidad en las empresas, se identifica a esta calidad primero como forma de control del producto y posteriormente como estrategia totalizante de los negocios, dentro de un proceso más amplio de toma de decisiones de los actores al interior de la organización productiva. La identificación de la empresa como una organización nos permite analizar sus orientaciones y objetivos particulares dentro de la división técnica del trabajo y tender un puente respecto a las estructuras contenidas en esta organización en términos de que esta es una síntesis del acontecer y de las necesidades de las sociedades humanas.

Tan solo pensemos lo siguiente: Durante el modo de desarrollo industrial la toma de decisiones estuvo permeada por la idea (si bien permanente en el capitalismo) de producir la mayor cantidad de bienes y servicios con los más bajos costos posibles. Esta obsesión se persiguió mediante las economías de escala que se sustentaron en la baja de los costos por unidad y en la maximización del rendimiento del proceso productivo para que el cliente tuviese una gran cantidad de productos, radicando la competencia interempresarial en 
ofertarlos al más bajo precio. El objetivo de todo actor que tomaba decisiones en las empresas era la maximización cuantitativa de los factores de la producción (tierra, trabajo y capital) para producir beneficios satisfactorios. La toma de decisiones tenía como enfoque de la estrategia del empresariado la idea de que la producción de un solo producto estandarizado permita incrementar el volumen de la producción sin hacer más grande la contratación de trabajadores; con ello, se evitaba el enfrentar la imposibilidad o incapacidad de producir con rapidez una diversidad de bienes y servicios. Además, se apostaba a reducir los gastos en investigación aplicada a la producción y el costo derivado de la distribución y circulación de los nuevos productos; también se aprovecharían las economías de escala y se ahorraría tiempo al evitar el cambio de productos en las empresas. El conocimiento aplicado se orientaba a optimizar y eficientizar el proceso productivo y a elevar la escala y la rapidez de la producción con maquinaria que dependiera del más bajo número de trabajadores. La decisión que buscaba aumentar la velocidad del proceso productivo consistía en reemplazar a la fuerza de trabajo por un bien de capital (Valdés, 1994, p. 63). Las decisiones dentro de esa carrera por maximizar las ganancias se enfocaban a la instrumentación de tecnologías que impulsaran una mayor escala, volumen y velocidad de la maquinaria y los sistemas para generar productos estandarizados, masivos y a bajo precio. Es así como las decisiones que constituyen estrategias empresariales se orientaban a mantener la distribución de bienes y servicios en los mercados; estas decisiones se caracterizaban por ser centralmente planificadas debido a su estructura piramidal sustentada en el Director General.

Ya en el modo de desarrollo informacional es el conocimiento aplicado al mismo conocimiento para lograr la innovación y aplicado al proceso productivo para agregar valor como objetivación del trabajo humano, lo que determina gran parte de la toma de decisiones en las empresas. En esta toma de decisiones se asume que todo lo relacionado con la producción es un proceso de cambio dinámico, constante y permanente, por lo que es necesario la evolución y la capacidad de adaptación de las estrategias de la organización. En la toma de decisiones está presente la constante reestructuración de las estructuras organizacionales de la empresa, las cuales al mismo tiempo redefinen la manera en que se crean, toman y procesan las decisiones. Otro elemento a considerar en la toma de decisiones es el proceso de trabajo, que para el caso de los países centrales es trabajo de conocimiento desarrollador de conocimiento aplicado al 
mismo conocimiento y al proceso productivo, es decir, la importancia del conocimiento como rasgo agregado a los factores de la producción está determinando la forma en que se crean las decisiones empresariales, y al mismo tiempo está constituyendo un nuevo actor caracterizado por la manipulación simbólica y por su capacidad para agregar valor a la economía mundial a partir de su conocimiento, de su competencia, sus contactos financieros y políticos, así como su versatilidad para adaptarse a cualquier entorno cultural. Este nuevo actor es el llamado analista simbólico (Reich, 1993).

La necesidad de analizar a la nueva empresa, al nuevo perfil del empresariado y los procesos de toma de decisiones implica un abordaje multidimensional que no solo enfoque al empresario como un actor político en relación al Estado, ni que coloque a la empresa como un indicador económico, o bien que aún cuando se estudien los sistemas económicos y se piense al capitalismo en sus dimensiones estructurales deje de contemplarse a los distintos actores y motivaciones que lo impulsan.

Dimensiones como la expansión del empresariado y sus empresas fuera de sus fronteras nacionales; su inserción en las redes empresariales globales; la presión para la articulación de determinada política pública que contribuya a la creación de mercados; los cada vez más acentuados cambios de las inversiones que están llevando a una metamorfosis del empresariado al dejar de invertir en la planta productiva tradicional y en fuentes de energía no renovables tras enfocar dichas inversiones a los monopolios que se constituyen con el control, dominio y acceso de las tecnologías, los flujos financieros, los recursos naturales, las comunicaciones (vías de comunicación como aviación, ferrocarriles, etc., y medios de comunicación como el Internet, la televisión, etc.), las armas de destrucción masiva (Amin, 1998 y 2001), la planta productiva ubicada en la periferia, y las decisiones gubernamentales, son todos ellos garantizadores de las relaciones asimétricas entre el centro y la periferia; conjuntamente con las inversiones destinadas a los nuevos ejes tecnológicos acumuladores de la riqueza: la electroinformática/robótica, la ingeniería genética/biotecnología, las nuevas energías, y la exploración de nuevos materiales/nanotecnología (Delgado, 2001). ¿Hacia donde se destinan las inversiones? ¿desarrollo de tecnología generadora de riqueza o fomento del aparato productivo? ¿qué criterios concibe el empresariado en la dirección tomada por las inversiones? ¿qué tipo de inversiones se privilegian en el proceso de toma de decisiones? 
Es la toma de decisiones empresariales una de las acciones que nos permiten comprender la nueva articulación de la división técnica del trabajo, la cual constituye a la empresa como una organización desconcentrada en cuanto al proceso productivo y a los niveles de toma de decisiones; esta fragmentación del proceso productivo conforma a los productos finales como derivados de insumos internacionales; es esta producción y comercialización de bienes y servicios diversificados en ciclos cortos y fraccionados, que responden a las necesidades específicas del cliente, lo que está constituyendo una nueva división internacional del trabajo que impulsa a la globalización en tanto proceso organizacional y sociocultural. Es la toma de decisiones empresariales y las formas de organización de la división técnica del trabajo lo que está constituyendo también una división social del trabajo que cada vez resulta más ambiguo categorizarla en sector agropecuario, sector industrial y sector servicios sobretodo si pensamos que aquellas empresas que tradicionalmente producían bienes se están convirtiendo en empresas de servicios o en gran medida estos ocupan una porción amplia de sus procesos productivos y cada vez menos sus productos son derivados del proceso industrial.

En suma, estos y otros pendientes es necesario enfrentarlos conceptualmente superando una postura de denuncia desde las ciencias sociales latinoamericanas. La postergación de esto nos está conduciendo a una falta de claridad conceptual sobre los actuales procesos, los actores sociales involucrados y sus manifestaciones en América Latina.

\section{REFERENCIAS}

Acevedo López, María guadalupe. (1996): "Las formas de organización empresarial que promueven la globalización de las economías", en la Revista Estudios Latinoamericanos, México, Facultad de Ciencias Políticas y Sociales de la UNAM, núm. 6, Nueva Época, año 3, julio-diciembre, pp. 69-82.

Acevedo López, María guadalupe. (1998): "Nuevos procesos de decisión y estructuras de poder en la era de la globalización" en Rosa María Piñón Antillón (Coordinadora), "La regionalización del mundo: la Unión Europea y América Latina, México, Facultad de Ciencias Políticas y Sociales de la Universidad Nacional Autónoma de México y Delegación de la Comisión Europea en México, Primera Edición, pp. 161-195.

Amin, Samir. (1998): "Capitalism in the age of globalization", London: Zed Books.

Amin, Samir. (2001): “'Globalización o Apartheid a Escala Global?”, en Globalización: Revista Web Mensual de Economía, Sociedad y Cultura, Septiembre, http://rcci.net/globalizacion/ 
Bagú, Sergio. (1994): "Tiempo, realidad social y conocimiento", México, Siglo Veintiuno Editores, Decimoctava Edición, (Primera Edición: 1970), 214 pp.

Bagú, Sergio. (1989): "La idea de dios en la sociedad de los hombres", México, Siglo Veintiuno Editores, Primera Edición, 173 pp.

Basave Kunhardt, Jorge (Coord.). (2000): "Empresas mexicanas ante la globalización", México, Instituto de Investigaciones Económicas de la UNAM y Editorial Miguel Angel Porrúa, Primera Edición, 338 pp.

Bell, Daniel. (1994): "El advenimiento de la sociedad postindustrial", España, Alianza Universidad, Primera Edición (en ingles: 1973), 578 pp.

Bergesen, Albert Y Fernández, Roberto. (1999): ¿Quién posee las 500 empresas líderes mencionadas por Fortune?, en Saxe-Fernández, John (Coordinador), "Globalización: crítica a un paradigma", México, Editorial UNAM, Instituto de Investigaciones Económicas, Dirección General de Apoyo al Personal Académico, Plaza Janés, Primera Edición, pp.247-287.

Castells, Manuel. (1998): "Globalización, tecnología, trabajo, empleo y empresa", en Revista La Factoría, octubre, No 7, www.lafactoriaweb.com/articulos/castells7.htm

Castells, Manuel. (2000): "La ciudad de la nueva economía", 1 de agosto de 2000, consultado en www.rebelion.org. Conferencia pronunciada en el Salón de Ciento del ayuntamiento de Barcelona el 21 de febrero.

Castells, Manuel. \& Hall, Peter. (1994): "Las tecnópolis del mundo. La formación de los complejos industriales del siglo XXI", España, Alianza Editorial, Primera Edición.

Coase, Ronald H. (1996): "La naturaleza de la empresa" (Edición en inglés: 1937), en Williamson, Oliver E. y Winter, Sidney G., "La naturaleza de la empresa. Orígenes, evolución y desarrollo", México, Fondo de cultura económica, Primera Edición, 1996 (Primera Edición en inglés: 1991), pp. 29-48.

Coase, Ronald H. (1994): "La empresa, el mercado y la ley", Madrid, Alianza Editorial, Primera Edición en Español, 219 pp.

Chudnovsky, Daniel, Kosacoff, Bernardo Y López, Andrés, con la colaboración de Celso Garrido. (1999): "Las multinacionales latinoamericanas. Sus estrategias en un mundo globalizado", Argentina, Fondo de Cultura Económica, Primera Edición, 396 pp.

Delgado Ramos, Gian Carlo. (2001): "El carácter geoeconómico y geopolítico de la biotecnología a fines del siglo XX", Tesis de Licenciatura para la Facultad de Economía de la Universidad Nacional Autónoma de México, Julio.

Drucker, Peter F. (1991): "La innovación y el empresario innovador. La práctica y los principios", México, Editorial Hermes, 1991 (Primera Edición en ingles en 1985), 307 pp.

Drucker, Peter F. (1994): "La sociedad postcapitalista", Colombia, Editorial Norma, Primera Edición, 244 pp.

Drucker, Peter F. (1996): "Su visión sobre: La administración. La Organización basada en la información, La economía, La sociedad”, Colombia, Editorial Norma, Primera Edición, 318 pp. 
Drucker, Peter F. (2001): "Detrás de la Revolución de la Información", en Revista La Factoría, octubre-enero, No 13, www.lafactoriaweb/com/articulos/drucke13.htm

Dunning, John. (1993): "Multinational enterprises and the global economy", Wokingham, England, Addison-Wesley Publishing Co.

Garrido, Celso (Coord.). (1998): "Empresarios y Estado en América Latina”, México, Centro de Investigación y Docencia Económica,Fundación Friedrich Ebert, Universidad Nacional Autónoma de México y Universidad Autónoma Metropolitana-Azcapotzalco, Primera Edición, pp.374.

Garrido, Celso \& Puga, Cristina. (1990): "Transformaciones recientes del empresariado mexicano", en Revista Mexicana de Sociología, México, Instituto de Investigaciones Sociales de la UNAM, año 52, núm. 2, abril-junio, pp. 43-61.

Giddens, Anthony. (1990): "The consequences of modernity", Cambridge: Polity press.

Gilroy, Bernard Michael. (1993): "Networking in multinational enterprises. The Importance of strategic alliances", South Carolina, University Carolina Press.

Guillen, Mauro F. (1989): "La profesión de economista. El auge de economistas, ejecutivos y empresarios en España", España, Editorial Ariel, Primera Edición, 337 pp.

González Casanova, Pablo. (1998): "Los indios de México hacia el nuevo milenio", en La Jornada, 9 de septiembre, p. 12.

Held, David. (1995): "Democracy and the global order: From the Modern State to Cosmopolitan Governance", Cambridge: Polity Press.

Hymer, Stephen Herbert. (1972): "Empresas multinacionales: la internacionalización del capital", Buenos Aires, Editorial Periferia, Primera Edición, 174 pp.

Hymer, Stephen Herbert. (1976): "The international operations of national firms: A study of direct foreign investment", Cambridge, Massachusetts, M.I.T., 253 pp.

Hymer, Stephen Herbert. (1979): "The multinational corporation: A radical approach", Cambridge, England, Cambridge University Press, 323 pp.

Ianni, Octavio. (1996): "Teorías de la Globalización", México, Centro de Investigaciones Interdisciplinarias en Ciencias y Humanidades de la UNAM y Siglo Veintiuno Editores, Primera Edición, 173 pp.

Ianni, Octavio. (1999): "La era del globalismo", México, Siglo XXI editores, Primera Edición.

Kanter, Rosabeth Moss. (2000): "La nueva clase directiva mundial. Progreso local en la economía global”, España, Editorial Paidós, Primera Edición, 444 pp.

Marx, Carlos. (1970): "Introducción: Producción, consumo, distribución, cambio (circulación)", en "Fundamentos de la crítica de la economía política" (Tomo I), La Habana, Instituto del Libro, pp. 23-47.

Millán, René. (1988): "Los empresarios ante el estado y la sociedad", México, Instituto de Investigaciones Sociales de la UNAM y Siglo XXI Editores, Primera Edición, 194 pp.

Morales, Josefina. (S.F.) "La maquila en México, Centroamérica y el Caribe", investigación de doctorado en curso, Mimeo.

Pérez Lizaur, Marisol Y Gándara Mendoza Leticia. (2001): "Los altos ejecutivos de las corporaciones transnacionales: un esbozo analítico para su estudio en México", en la 
Incursiones en torno a la teorización sobre la transformación del empresariado y la toma de decisiones en la

era de la globalización

Revista Estudios Sociológicos, El Colegio de México, número 56, año XIX, mayoagosto, pp. 419-438.

Petras, James. (2001): "La revolución informática, la globalización y otras fábulas imperiales" en: John Saxe-Fernández y James Petras, "Globalización, imperialismo y clase social", Argentina, Editorial Lumen-Hvmanitas, Primera Edición, 342 pp.

Petras, James. (2001): "El mito de la tercera revolución científico-tecnológica en la era del imperio neomercantilista", 28 de julio, consultado en www.rebelion.org

Porter, Michael E. (1993): "La ventaja Competitiva de las Naciones", Argentina, Javier Vergara Editor, 1025 pp.

Pozas, Ricardo Y Luna, Matilde (Coords.). (1991): "Las empresas y los empresarios en el México contemporáneo”, México, Editorial Grijalbo, Primera Edición, 632 pp.

Puga, Cristina. (1993): "México: empresarios y poder", México, Facultad de Ciencias Políticas y Sociales de la UNAM y Editorial Miguel Angel Porrúa, Primera Edición.

Reich, Robert B. (1993): "El trabajo de las naciones. Hacia el capitalismo del siglo XXI", Argentina, Javier Vergara Editor, Primera Edición, 314 pp.

Rueda Peiro, Isabel. (2001): "Las Micro, Pequeña y Mediana empresas en México en los noventa", México, Instituto de Investigaciones Económica de la U.N.A.M. y Editorial Miguel Angel Porrúa, Primera Edición, 78 pp.

Salas-Porras, Alejandra. (1992): "Globalización y proceso corporativo de los grandes grupos económicos en México", en la Revista mexicana de Sociología, México, Instituto de Investigaciones Sociales de la UNAM, año LIV, abril-junio, no. 2, pp. 133-162.

Salas-Porras, Alejandra. (1997): "Estructuras, agentes y constelaciones corporativas en México durante la década de los noventa", en la Revista Mexicana de Sociología, México, Instituto de Investigaciones Sociales de la UNAM, año LIX, num. 4, octubrediciembre, pp. 47-92.

Salas-Porras, Alejandra. (1998): "Estrategias de las empresas mexicanas en sus procesos de internacionalización, en la Revista de la Comisión Económica Para América Latina (CEPAL), Naciones Unidas, número 65, agosto, 20 pp.

Salas-Porras, Alejandra. (2000): “¿Hacia un nuevo mecenazgo político? Democracia y participación electoral de los grandes empresarios en México", en Revista Estudios Sociológicos, México, El Colegio de México, año XVIII, núm. 52, pp. 53-84.

Saxe-Fernández, John. (1999): "Globalización e imperialismo", en SAXE-FERNÁNDEZ, JOHN (Coord.), "Globalización: crítica a un paradigma", México, Editorial UNAM, Instituto de Investigaciones Económicas, Dirección General de Apoyo al Personal Académico, Plaza Janés, Primera Edición, pp 9-68.

Saxe-Fernández, John \& NúÑEZ RODRÍGUEZ, OMAR. (S.F.): "Globalización e imperialismo: la transferencia de excedentes de América Latina", en John Saxe-Fernández y James Petras, "Globalización, imperialismo y clase social", Argentina, Editorial LumenHvmanitas, Primera Edición, 342 pp.

Tirado, Ricardo (Coord.). (1994): "Los empresarios ante la globalización", México, Instituto de Investigaciones Legislativas de la H. Cámara de Diputados, LV Legislatura e Instituto de Investigaciones Sociales de la UNAM, Primera Edición. 
Touraine, Alain. (1987): "La empresa en la historia", Programa Informateca, Encyclopedia Britannica, Programa de 10 años, 16 pp. (publicado originalmente en Revue Francaise d'Administración Publique, no 42, abril-junio).

Valdés, Luigi. (1994): "Conocimiento es futuro. Hacia la sexta generación de los procesos de calidad", México, Concamin, CCTC, Funtec, 420 pp.

Vernon, Raymond. (S.F.): "La ética y las empresas transnacionales", Programa Informateca, Encyclopedia Britannica, Programa de 10 años, 5 pp. (publicado originalmente en Society, extractado de Informe Bibliográfico).

Vernon, Raymond. (1973): "Soberanía en peligro: la difusión multinacional de las empresas de Estados Unidos", México, Fondo de Cultura Económica, Primera Edición (Primera Edición en Inglés: 1971), 290 pp.

Vernon, Raymond. (1980): "Tormenta sobre las multinacionales: las cuestiones esenciales", México, Fondo de Cultura Económica, Primera Edición (Primera Edición en Inglés: 1977), 283 pp.

Vilas, Carlos M. (1999): "Seis ideas falsas sobre la globalización", en Saxe-Fernández, John (Coordinador), "Globalización: crítica a un paradigma", México, Editorial UNAM, Instituto de Investigaciones Económicas, Dirección General de Apoyo al Personal Académico, Plaza Janés, Primera Edición, pp 69-101.

Vidal, Gregorio. (2000): "Grandes empresas, economía y poder en México"; México, Plaza y Valdés y Universidad Autónoma Metropolitana-Iztapalapa, Primera Edición, 236 pp.

Williamson, Oliver E. (1989): "Las instituciones económicas del capitalismo", México, Fondo de Cultura Económica, Primera Edición (Primera Edición en Inglés: 1985), 435 pp.

Williamson, Oliver E. (1996): "La lógica de la organización económica", en Williamson, Oliver E. y Winter, Sidney G., "La naturaleza de la empresa. Orígenes, evolución y desarrollo", México, Fondo de cultura económica, Primera Edición (Primera Edición en inglés: 1991), pp. 126-162.

Winter, Sidney G. (1996): "Coase, la competencia y la corporación”, en Williamson, Oliver E. y Winter, Sidney G., "La naturaleza de la empresa. Orígenes, evolución y desarrollo", México, Fondo de cultura económica, Primera Edición (Primera Edición en inglés: 1991), pp. 248-270.

\section{NOTAS}

1) Para Daniel Bell (1994), el conocimiento es una serie de afirmaciones organizadas de hechos o ideas que presentan un juicio razonado o un resultado experimental, que se transmite a los demás mediante algún medio de comunicación en alguna forma sistemática.

2) La Información es el conjunto de datos organizados y dispuestos a ser comunicados y difundidos.

3) Es en expresiones como la dependencia y la interdependencia entre otras más, en que la globalización se manifiesta en América Latina como un proceso de transferencia de valor y plusvalor vía la integración a las redes empresariales globales tras las "ventajas comparativas" ofrecidas por la región, y como un proceso de trasferencia de excedentes vía la fuga de capitales, el deterioro de los términos de intercambio, el servicio de la deuda, transferencias unilaterales, utilidades netas, y errores y omisiones, pues de 1976 a 1997 se tributaron desde América Latina a otras regiones del mundo 2 billones, 051 mil 619.1 millones de dólares mediante estos rubros (Saxe-Fernández y Nuñez, 2001). De esta forma, los procesos de intercomunicación, interacción e 
interdependencia planetaria en tiempo real se entrelazan a los característicos ingredientes de subsunción, dominación y expropiación/apropiación.

4) La primera etapa caracterizada por el predominio del capital financiero, esto es, una subordinación de las empresas a la dinámica de los grandes banqueros y financieros industriales "donde el espíritu de la empresa no es definido por la gestión de una organización sino, de manera propiamente capitalista, como de la búsqueda de un beneficio que corresponda a los riesgos corridos por los capitales" (Touraine, p. 2), es una etapa en la que el actor principal es el capitalista; la segunda etapa es la llamada sociedad industrial que se caracteriza por la racionalización de la organización laboral y productiva dentro de la fábricas (taylorismo) y por la aplicación de la ciencia a la industria (Fordismo), contando también con un predominio de un modelo gerencial de toma de decisiones y de acción en las empresas basado en las "reglas del pensamiento racionalista", con lo cual la empresa se convierte en el centro de la vida social y política de la época, teniendo como actores predominantes a los organizadores; y la tercera etapa que corresponde a la sociedad postindustrial con los estrategas volcados al exterior como los actores más destacados, se caracteriza por estar envuelta en el torbellino de los cambios en los problemas a enfrentar por los empresarios en las organizaciones, esto es, se transita del funcionamiento, de los conflictos y las negociaciones al desarrollo, la innovación y la competencia, por lo que se concibe a la empresa como agente del cambio económico al reemplazar los principios de la racionalización por los objetivos particulares de la estrategia y al fusionar los aspectos económicos, sociales y políticos de su funcionamiento y al asumir un modelo militar.

5) La concepción ortodoxa del libro de texto es una categoría introducida por Sidney G. Winter (1996) para referirse a la teoría ortodoxa de la empresa asumida por los economistas y expresada en obras de economía del trabajo, de teoría de la empresa, de producción y costos, de oferta competitiva, de econometría aplicada que se refiera al comportamiento de la empresa. Respecto a estos estudios, otros autores como Matin Shubik señalan que "mientras más elemental sea el libro de texto, más probable será que contenga información sobre diferentes formas organizativas. Sin embargo, en cuanto nuestro estudio se vuelve avanzado, ya no nos molestaremos en diferenciar entre la General Motors y la dulcería local". Más aun para Winter, esta concepción "no ofrece ninguna base para la comprensión de los incentivos y los procesos de las empresas que producen el cambio tecnológico y organizativo" (1986, p. 258), lo cual se relaciona con su inadecuación en la explicación de las fronteras de la empresa, y con la omisión total del problema de la actuación efectiva de las empresas en la tarea de almacenamiento del conocimiento que se encuentra detrás de la competencia productiva.

6) La publicación del clásico artículo de Ronald Harry Coase titulado "La naturaleza de la empresa" se realizó en 1937 con el título original de "The Nature of the Firm" en el número 4 de Económica, pp. 386-405, y posteriormente tras un homenaje a su obra es compilado por Oliver E. Williamson y Sidney G. Winter (1996 en la versión castellana).

7) Sobre esta centralidad del empresariado algunos autores sostienen que "a lo largo de tres sexenios presidenciales, la sociedad mexicana ha presenciado la irrupción en la escena política de un empresariado que, sorpresivamente, abandonó su tradicional discreción relativa a los asuntos públicos para demandar la ampliación de sus márgenes de participación y que, respaldado por su gran poder económico, promovió un nuevo proyecto de país. La coincidencia de muchos de sus planteamientos con los de una nueva generación de líderes políticos ha llevado a la reformulación del modelo de desarrollo y a transformaciones fundamentales en el Estado mexicano" (Puga, 1993, p. 9).

8) En estos estudios una preocupación constante es reflejada por Gregorio Vidal (2000): La situación de sobrevivencia que impera ante el modo en que se presenta la apertura comercial, coloca a los consorcios (aunque no pretendan la internacionalización) en la necesidad de competir con las más importantes firmas, lo cual implica un cambio profundo en la toma de decisiones en materia de inversión y en el modo en que se está financiando, lo cual implica que las decisiones de inversión de las corporaciones que actúan en territorio mexicano se toman en función del comportamiento que existe en los mercados externos, mientras que las empresas que se internacionalizan conjuntamente con sus estados financieros está vinculados a la manera en que se comportan las inversiones en el exterior. Además, la acumulación que es financiada por mecanismos que están más allá de las fronteras nacionales y la reestructuración de los grupos empresariales es una fuerza más de este proceso, esto es, las ganancias financieras generadas en otra época han estado financiando el proceso 
de integración con la economía norteamericana, por lo que se mantendrá la compra-venta de empresas, con entradas y salidas considerables de capital. "En este escenario inestable el problema es cómo los consorcios y grupos financieros que están al frente del proceso económico y que no tienen garantizada su permanencia, logran ampliar la esfera de su dominación y generar modos de legitimación y de consenso activo. El crecimiento de grandes inversionistas en la condición de socios de capitalistas del exterior o simplemente de rentistas, limita las posibilidades de construir una propuesta para un amplio conjunto de fuerzas sociales y le da fuerza a un proyecto basado en el dominio de la financiarización de la economía" (p. 176)

CONTACTO: isaacep@correo.unam.mx

REVISTA MAD | MAGíSTER EN ANÁLISIS SISTÉMICO APLICADO A LA SOCIEDAD | ISSN 0718-0527
Departamento de Antropología | Facultad de Ciencias Sociales | Universidad de Chile
Avenida Capitán Ignacio Carrera Pinto 1045 Nuñoa $7800284 \mid$ Santiago | Chile
$+56229787760 \mid$ revistamad.uchile@facso.cl |www.revistamad.uchile.cl
Twitter y Facebook: @RevMadUChile

